Document downloaded from:

http://hdl.handle.net/10251/52083

This paper must be cited as:

Taleb, Z.; Montilla, F.; Quijada Tomás, C.; Morallón, E.; Taleb, S. (2014). Electrochemical and In Situ FTIR Study of o-Cresol on Platinum Electrode in Acid Medium. Electrocatalysis. 5(2):186-192. doi:10.1007/s12678-013-0182-x.

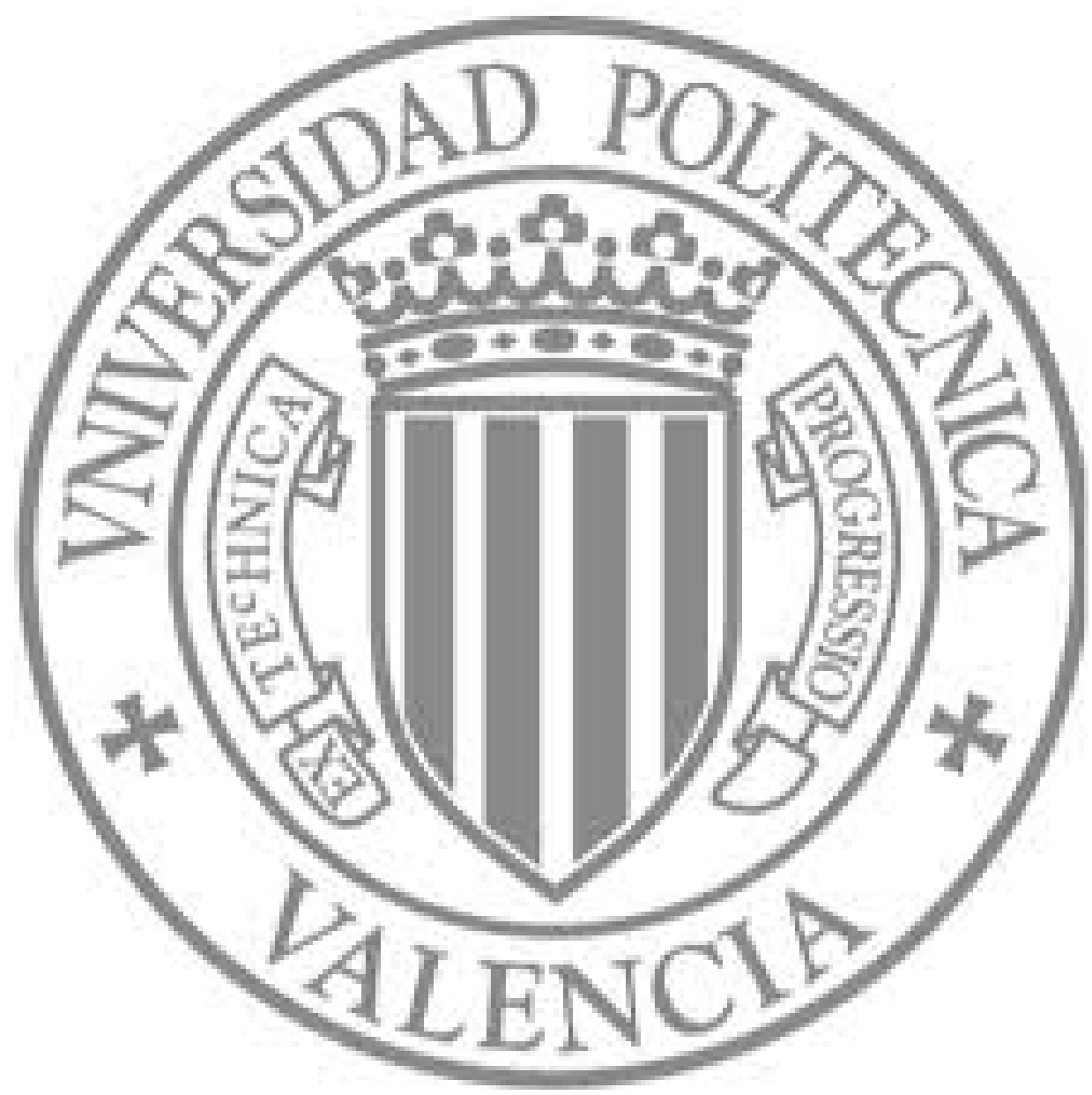

The final publication is available at

http://dx.doi.org/10.1007/s12678-013-0182-x

Copyright Springer Verlag (Germany) 


\section{Electrocatalysis \\ Electrochemical and in situ FTIR study of o-cresol on platinum electrode in acid medium \\ --Manuscript Draft--}

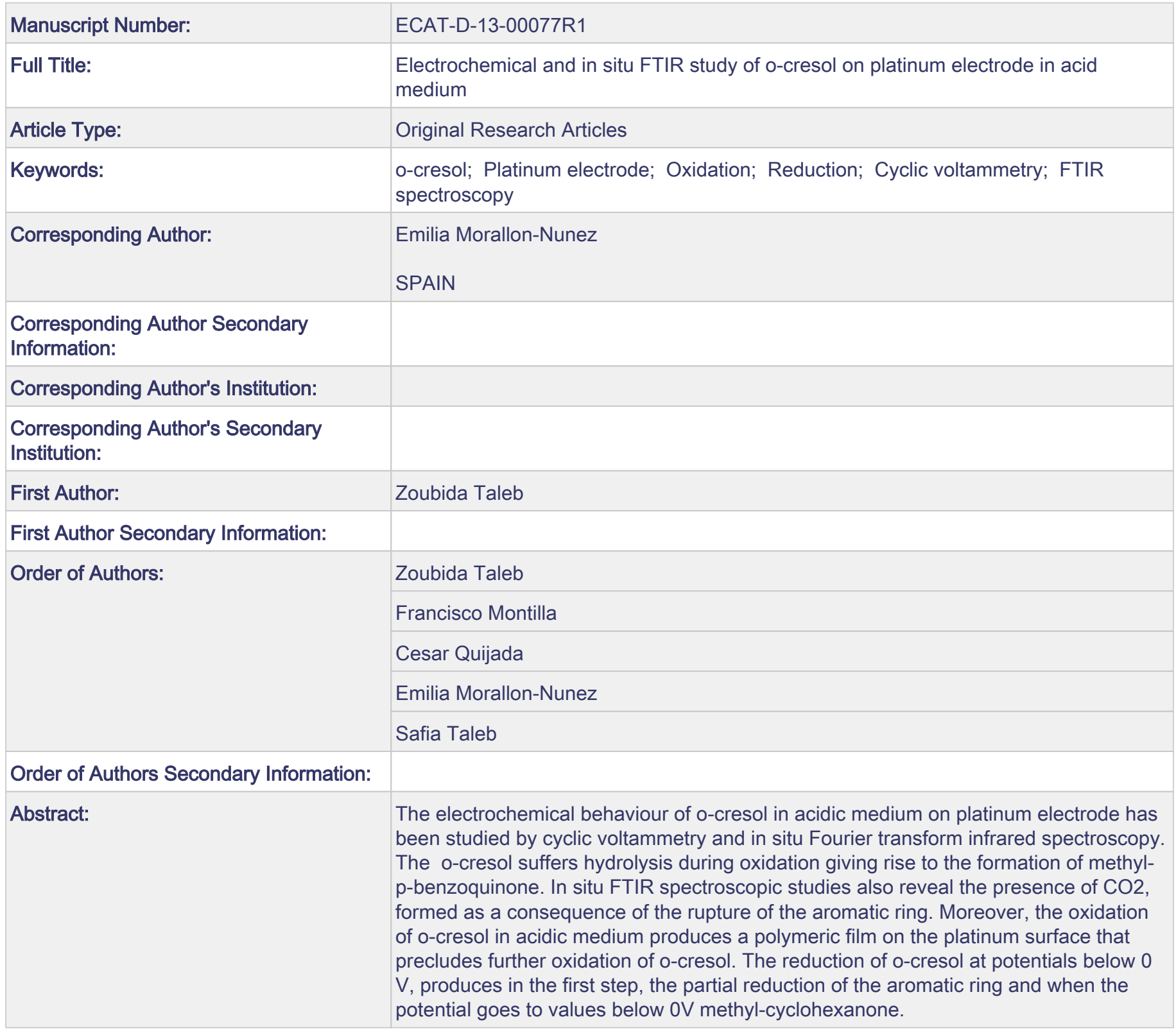




\title{
Electrochemical and in situ FTIR study of o-cresol on platinum electrode in acid medium
}

\author{
Z. Taleb ${ }^{1}$, F. Montilla ${ }^{2}$, C.Quijada ${ }^{3}$, E.Morallon ${ }^{2, *}$ and S.Taleb ${ }^{1}$ \\ ${ }^{1}$ Laboratoire de Matériaux \& Catalyse, Faculté des Sciences, Université Djillali Liabès \\ BP89, Sidi-Bel-Abbès (Algerie) \\ ${ }^{2}$ Instituto Universitario de Materiales, Departamento de Química Física, Universidad de \\ Alicante, Apartado 99, 03080 Alicante, España \\ ${ }^{3}$ Departamento de Ingeniería Textil y Papelera, Universitat Politècnica de València, Pza. \\ Ferrandiz y Carbonell, 03801, Alcoy (Alicante).España.
}

\begin{abstract}
The electrochemical behaviour of o-cresol in acidic medium on platinum electrode has been studied by cyclic voltammetry and in situ Fourier transform infrared spectroscopy. The ocresol suffers hydrolysis during oxidation giving rise to the formation of methyl-pbenzoquinone. In situ FTIR spectroscopic studies also reveal the presence of $\mathrm{CO}_{2}$, formed as a consequence of the rupture of the aromatic ring. Moreover, the oxidation of o-cresol in acidic medium produces a polymeric film on the platinum surface that precludes further oxidation of $\mathrm{o}$-cresol. The reduction of o-cresol at potentials below $0 \mathrm{~V}$, produces in the first step, the partial reduction of the aromatic ring and when the potential goes to values below 0V methylcyclohexanone.
\end{abstract}

Keywords: o-cresol; Platinum electrode; Oxidation; Reduction; Cyclic voltammetry; FTIR spectroscopy.

*Corresponding author: E. Morallón, morallon@ua.es, Telf.: +34-965909590 


\section{Introduction}

The adsorption and reactivity of organic compounds at the electrode/electrolyte interface is a subject of general interest in electrocatalysis and in electrochemical surface science. The electrosorption properties and reactivity of several aromatic compounds, i.e. benzene, toluene, phenol or benzoic acid on metallic surfaces have been quite well studied for years[1,2,3].

The electrochemical reactivity of the aromatic compounds is strongly related to the interaction of the compound with the metallic surface. The adsorbate structure and mode of bonding of these aromatic compounds control their electrochemical reactivity [3]. The simplest aromatic compound (benzene) suffers different electrochemical reductions depending on the electrode surface and on $\mathrm{pH}[4-6]$

The reduction of benzene yields cyclohexane and this reaction is concomitant to the Hydrogen Evolution Reaction (HER) since cyclohexane is produced by the presence of adsorbed hydrogen at low (over)potentials [7]. Therefore the formation of this product requires adsorbed benzene on the electrode at the potential of HER.

While in acidic medium benzene is electrochemically reduced to cyclohexane and also desorbed, in alkaline medium this reaction is not produced as consequence of the high overpotential of hydrogen evolution reaction in comparison to acid solution [8,9]. Very similar behaviour is reported for other aromatic compounds like toluene or xylene [10].

On the other hand the electrochemical oxidation of benzene or toluene in acidic media yields $\mathrm{CO}_{2}$, benzoquinone and $\alpha, \beta$-unsaturated esters or lactones, produced in the oxidative breaking of the aromatic ring. However, in alkaline medium the oxidation of aromatic compounds produces the rupture of the aromatic ring yielding carbonate anions coming from $\mathrm{CO}_{2}$ and salts of carboxylic acids [8,11].

The presence of electronegative side groups attached to the aromatic ring modifies the electrochemical reactivity (i.e. benzoic acid). For example, it is usual to observe changes in the adsorption orientation of benzoic acid onto metallic electrodes. At potentials less positive than $0.5 \mathrm{~V}$ vs RHE a reorientation of the organic compound is detected, passing from a perpendicular adsorption in a two-fold coordination through the carboxylate group to a parallel adsorption (through the aromatic ring). At potentials more positive than $0.5 \mathrm{~V}$, an 
increase of the surface coverage of benzoate anions adsorbed through the carboxylate group happens, reaching a maximum at $0.8 \mathrm{~V}$. This behaviour has been observed for platinum and gold electrodes [12]. Other substituted aromatic compounds like hydroquinone (HQ) have been also studied on platinum electrodes [13]. According to these authors, hydroquinone could adsorb in two orientational states at polycrystalline Pt surfaces. At concentrations below $0.1 \mathrm{mM}$ HQ solution a horizontal orientation with the aromatic ring parallel to the electrode surface is predominant, while adsorption from solutions more concentrated than $1 \mathrm{mM} H Q$ a vertical orientation with the ring nearly perpendicular to the Pt surface is reported.

The study of the electrochemical reactivity of aromatic compounds has a great importance and interest, because these compounds are used in many chemical processes. In addition to its applications, some of these aromatic compounds are highly hazardous pollutants of many industrial processes. For example, phenol and cresol are persistent organic compounds found in aqueous effluents from petroleum refineries, steel plants, dyeing manufacturing, pharmaceutical and plastic industries etc [14,15]. Electrochemical methods have been successfully used in the detection and elimination of some phenolic compounds because they are oxidized at readily accessible potentials [4-9].

There have been several electrochemical studies of phenolic compounds on $\mathrm{Pt}$ and $\mathrm{Au}$ electrodes in acid medium [21-25]. The mechanism for the oxidation of these compounds have been proposed $[21,22,25]$. It has been suggested that a free radical is formed during the initial one-electron oxidation of cresol. The coupling of the radicals followed by intramolecular rearrangements results in the formation of dimeric products and/or long chain polymeric species $[21,22]$. This coupling is more favored in acidic media. It is well-known that phenolic compounds give polymeric products during their oxidation on platinum electrodes [21,23,26,27]. From FT-IR results, Gattrell and Kirk [21,22] postulated the structures for different films produced by oxidation of phenolic compounds ( $\mathrm{p}$-cresol, o,o'biphenol and phenol). In the case of phenol these authors proposed that the polymer contains a mixture of mostly directly linked phenol rings with some ether-linked rings. Polymeric films formed on Pt by electropolymerization of phenol in alkaline medium were analyzed by X-ray photoelectron Spectroscopy by Lapuente et al. [27], who suggested that films grown either potentiostatically or potentiodynamically possess a common structure of aromatic carbon rings linked through ether bonds with some ring positions occupied by hydroxyl groups. Ferreira et al. [23] studied the formation of polymeric products resulting from 
electrooxidation of phenolic compounds in aqueous solutions by different techniques (cyclic voltammetry, Fourier transform infrared spectroscopy (FTIR) and electrochemical quartz crystal microbalance) on $\mathrm{Au}$ and Pt electrodes. They concluded that the polymeric products formed from substituted phenol are more passivating than those from the unsubstituted phenol.

This work studies the electrochemical reactivity of o-cresol using platinum electrodes in acidic solutions. Cyclic voltammetry and in situ Fourier Transform Infrared spectroscopy have been combined to analyze the soluble products obtained on platinum electrodes.

\section{Experimental}

The test solutions were $0.5 \mathrm{M} \mathrm{H}_{2} \mathrm{SO}_{4}$ from Merck Suprapur concentrated acid. Ortho-cresol was supplied by Aldrich and was used as received. The water employed for the preparation of the solutions was obtained from an Elga Labwater Purelab system $(18.2 \mathrm{M} \Omega \mathrm{cm}) . \mathrm{D}_{2} \mathrm{O}$ was from Aldrich chemicals, 99.9\% atom \% D.

All electrochemical measurements were carried out in a conventional three-electrode cell. The counter electrode was a spiral of platinum wire and a reversible hydrogen electrode (RHE) immersed in the same solution using a Luggin was used as the reference electrode. A polycrystalline platinum electrode was used as working electrode and it was thermally cleaned and subsequently protected from the laboratory atmosphere by a droplet of ultrapure water.

Cyclic voltammograms were recorded at room temperature with a standard set-up equipment and at a sweep rate of $50 \mathrm{mV} \mathrm{s}^{-1}$.

A Nicolet Magna 850 spectrometer equipped with a liquid nitrogen-cooled MCT detector was employed for in situ FTIR measurements. The sample compartment was purged throughout the experiment using a 75-50 Balston clean air package. The electrode used was a polycrystalline platinum disc of $8 \mathrm{~mm}$ in diameter obtained from GoodfellowMetals (purity 99.99\%). The disc was mounted on a glass tube and its surface was polished using alumina powder of several sizes $(1,0.3$ and $0.05 \mu \mathrm{m})$ before the thermal treatment [11,12]. A platinum wire was used as counter electrode. 
The thin layer spectroelectrochemical cell was made of glass and was provided with a prismatic $\mathrm{CaF}_{2}$ window bevelled to $60^{\circ}$. Spectra were collected at $8 \mathrm{~cm}^{-1}$ resolution and are presented as $\Delta R / R$.

FTIR-ATR experiments were performed on a Nicolet 5700 equipped with a MCT detector and a diamond ATR crystal.

\section{Results and discussion}

Fig. 1 shows the voltammetric response obtained during the oxidation of $10^{-3} \mathrm{M}$ o-cresol in $0.5 \mathrm{M}$ sulfuric acid on a platinum electrode. The oxidation of o-cresol features a sharp and irreversible peak at $1.36 \mathrm{~V}$. The current density of this oxidation process decreases in the second cycle. During the subsequent cycles, the oxidation of o-cresol is gradually hindered until no anodic peak associated with the oxidation of o-cresol is observed in the fifth cycle. From this voltammetric behaviour, it could be stated that the products of o-cresol oxidation block the electrode surface, preventing o-cresol from further oxidation. Thus the behaviour observed in Fig. 1 can be associated with the formation of a non-conducting polymeric film on the electrode surface.

To confirm the existence of a polymeric film on the electrode surface, the covered electrode obtained after five sweeps up to $1.8 \mathrm{~V}$ as in Fig.1, was removed from the electrochemical cell and thoroughly washed with ultrapure water. Then, it was immersed in o-cresol-free $0.5 \mathrm{M}$ $\mathrm{H}_{2} \mathrm{SO}_{4}$ solution at $0.3 \mathrm{~V}$ and cycled between 0.06 and $1.6 \mathrm{~V}$ (Fig.2). It can be observed that the voltammogram is different from that obtained with a clean platinum electrode (Fig.2, dashed line). Most of the adsorption sites of the platinum surface are blocked, as indicated by the low electric charge recorded in the potential zone between 0.06 and $0.4 \mathrm{~V}$. The current density associated with the surface oxide is smaller than that obtained for the clean platinum electrode. Also, there is still an anodic current above $1.0 \mathrm{~V}$ whose charge is not counterbalanced by the charge in the subsequent reverse scan, thus pointing to a continuous oxidative degradation of the insulating thin film in the potential interval explored. 


\subsection{FTIR-ATR study.}

The ex situ ATR-FTIR spectrum of the polymer produced by electroxidation of $10^{-3} \mathrm{M}$ cresol in $0.5 \mathrm{M} \mathrm{H}_{2} \mathrm{SO}_{4}$ solution during $2 \mathrm{~h}$ at $1.8 \mathrm{~V}$ is shown in Figure 3.

The spectrum shows several bands in the range $1400-1600 \mathrm{~cm}^{-1}$ related with the aromatic $\mathrm{C}=\mathrm{C}$ stretching vibration, the strongest lying at around $1600 \mathrm{~cm}^{-1}$ which indicates that the polymeric film has an aromatic ring backbone. The band at $1457 \mathrm{~cm}^{-1}$ could be associated with a $\mathrm{C}=\mathrm{C}$ stretching vibration mode of trisubstituted benzenes, althought it may also be contributed by the asymmetric $\mathrm{C}-\mathrm{H}$ deformation vibration of methyl groups. The intense band at $1019 \mathrm{~cm}^{-1}$ can be ascribed to the $=\mathrm{C}-\mathrm{H}$ in-plane deformation vibration in aromatic rings. The strong and broad bands in the region $900-1150 \mathrm{~cm}^{-1}$ can be associated to the ether C-O symmetric and asymmetric stretching vibrations (=C-O- ring). Then, the oxygen group is retained in the polymer through an ether-linkage. The bands in the region $2800-3000 \mathrm{~cm}^{-1}$ could be associated with the methyl C-H stretching vibration. The bands at 2976 and 2934 $\mathrm{cm}^{-1}$ are typical of the out-of-phase $\mathrm{C}-\mathrm{H}$ stretch mode in aryl- $\mathrm{CH}_{3}$, whereas the broad band centred at $2874 \mathrm{~cm}^{-1}$ may involve the in-phase $\mathrm{C}-\mathrm{H}$ stretching modes and an overtone of the asymmetric C-H deformation band, typically arising at about 2925, 2855 and $2740 \mathrm{~cm}^{-1}$ respectively in methyl-substituted aromatic rings [28,29]. The spectrum also shows very strong bands between 1600 and $1800 \mathrm{~cm}^{-1}$. These bands could be associated with the stretching vibration of $\mathrm{C}=\mathrm{O}$; the presence of this group indicates the formation of quinonelike moieties. Then, this assignment suggests that the formed polymer is overoxidized under our experimental conditions as Fig. 2 shows. In summary, it can be concluded that the polymer formed under our experimental conditions does not present a defined structure: it probably comprises different oligomers with $\mathrm{C}-\mathrm{C}$ or $\mathrm{C}-\mathrm{O}-\mathrm{C}$ linkages and some oxidized structures with quinone groups.

\subsection{In situ FTIR study.}

In order to analyse the species produced during the oxidation and reduction of o-cresol, in-situ Fourier transform infrared (FTIR) spectroscopy experiments were performed.

Figure 4 shows the in situ FTIR spectra obtained for a platinum electrode in $0.5 \mathrm{M} \mathrm{H}_{2} \mathrm{SO}_{4}+$ $10^{-3} \mathrm{M}$ o-cresol solution during the oxidation (Fig. 4a) and reduction (Figure 4b) of o-cresol. 
These experiments were conducted with water as the solvent. After the flame treatment, the electrode was introduced in the working solution at $0.3 \mathrm{~V}$ and the reference spectrum was collected. The potential was then stepped to higher (Fig. 4a) or lower (Fig. 4b) values and 100 interferograms were collected at each step.

In Figure 4a (oxidation) a sharp band at $2345 \mathrm{~cm}^{-1}$ corresponding to the formation of $\mathrm{CO}_{2}$ arises at $0.8 \mathrm{~V}$ and increases abruptly at higher potentials. The onset of the $\mathrm{CO}_{2}$ band occurs at a lower potential than that observed during the oxidation of benzene in the same conditions $[8,29]$. The shift in the $\mathrm{CO}_{2}$ formation potential points to a destabilization of the aromatic ring against oxidation as consequence of the presence of two activating substituents. At a potential of $1.2 \mathrm{~V}$, an additional positive band around $1253 \mathrm{~cm}^{-1}$ associated to $\mathrm{C}-\mathrm{O}$ stretching vibration in phenolic compounds [28] indicates the disappearance of alcohol group.

The oxidation of phenol at a platinum electrode was studied in aqueous acidic solution by Gattrell and Kirk [21,22]. According to these authors, the oxidation of adsorbed phenol involves the ring cleavage. However, the phenol in solution reacts by rapid oxidation involving minimal rearrangement of the reactant molecule, implying the formation of benzoquine and polymer with ether structures. These molecules suffer posterior oxidation with the ring cleavage.

In Figure $4 \mathrm{~b}$ (reduction) no clear bands are observed when the potential was stepped down to 0.25 and $0.05 \mathrm{~V}$. Only when the potential reaches $-0.02 \mathrm{~V}$ (onset of the hydrogen evolution), two negative bands at 2923 and $2852 \mathrm{~cm}^{-1}$, together with a small band at $1455 \mathrm{~cm}^{-1}$ (not shown in the spectra of Figure $4 \mathrm{~b}$ ) are clearly observed. These bands can be assigned to the C$\mathrm{H}$ symmetric and asymmetric stretching of a methylene group $\left(-\mathrm{CH}_{2}-\right)$, respectively. The band at $1455 \mathrm{~cm}^{-1}$ can be associated to the $-\mathrm{CH}_{2}-$ scissor vibration of the same methylene group $[28,29]$. The presence of these bands strongly suggests the hydrogenation of the aromatic ring of the o-cresol molecule to yield methyl-substituted cyclic aliphatic rings. Similar bands were reported to occur during the electrochemical reduction on platinum electrodes of several aromatic compounds (benzene, toluene and benzoic acid) in aqueous solutions at different pHs [8,10-12]. It was observed that the reductive hydrogenation of the aromatic ring of such compounds occurs in acidic media concomitant to the reduction of water to hydrogen. This adsorbed hydrogen at lower overpotentials is responsible for the reduction the aromatic system that is adsorbed on the electrode surface, with the generation of a fully saturated ring. 
In order to avoid the interference of the water absorption band in the zone between 1640 and $1700 \mathrm{~cm}^{-1}$, the spectra were also obtained in deuterated water (Figure 5) using the same reference potential of $0.3 \mathrm{~V}$. Under these conditions, several bands are clearly observed. When the potential reaches a value of $0.8 \mathrm{~V}$ (Figure 5a) negative bands at 1653, 1500 and 1273 appear at $0.8 \mathrm{~V}$. The $1653-\mathrm{cm}^{-1}$ band increases sharply at higher potentials. At potentials above $1.2 \mathrm{~V}$, two additional, well-discerned negative bands at 1629 and $1603 \mathrm{~cm}^{-1}$ arise. The $1500 \mathrm{~cm}^{-1}$ band is however absent at these high potentials. The negative band at $1653 \mathrm{~cm}^{-1}$ could be associated with $\mathrm{C}=\mathrm{O}$ stretching vibration and which indicates that this functional group is formed during the oxidation of o-cresol. In fact, the spectrum of methyl-pbenzoquinone shows intense bands at 1660, 1603 and $1290 \mathrm{~cm}^{-1}$ [30]. Then, it can be concluded that o-cresol is oxidized to methyl-p-benzoquinone. The origin of the band at 1629 $\mathrm{cm}^{-1}$ is uncertain, but it probably corresponds to different types of quinonic compounds, perhaps of oligomeric or polymeric nature.

At a potential of $0.8 \mathrm{~V}$ or above, positive bands also appear at 1578, 1447, 1365 and 1233 $\mathrm{cm}^{-1}$. The intensity of these bands also increases upon raising the potential. The two former bands can be related to aromatic $>\mathrm{C}=\mathrm{C}<$ stretching modes of the o-cresol that is being desorbed from the electrode surface at such positive potentials. The absorptions at 1365 and $1233 \mathrm{~cm}^{-1}$ can correspond to combination bands of the $\mathrm{OH}$ deformation and $\mathrm{C}-\mathrm{O}$ stretching modes in o-substituted phenols, yet the former feature could also be contributed by the symmetric $\mathrm{C}-\mathrm{H}$ deformation vibration of the methyl group. The sign of these bands points that o-cresol is being desorbed and the molecule looses the alcohol group to be transformed into quinone species.

The bands at $1578\left(1576 \mathrm{~cm}^{-1}\right.$ in Figure 5b), 1447 and 1365 also appear when the potential is stepped down below $0.3 \mathrm{~V}$ (Figure $5 \mathrm{~b}, 0.25-0.0 \mathrm{~V}$ ), but with opposite sign. Further, the band at $1576 \mathrm{~cm}^{-1}$ is potential-dependent and shifts to lower wavenumbers upon decreasing the potential within the range $0.2-0.0 \mathrm{~V}$. This result is a strong evidence of the interaction of the surface and the o-cresol molecule, this is, the modes vibrating at $1576 \mathrm{~cm}^{-1}, 1447$ and 1365 $\mathrm{cm}^{-1}$ belong to an adsorbed species. The observed increase in the intensity of these bands can be the result of the rising in the surface concentration of adsorbed o-cresol with the decreasing potential. In accordance with this view, the bands at 1592 and $1500 \mathrm{~cm}^{-1}$ (positive in Figure $5 b)$ could be assigned to aromatic $>\mathrm{C}=\mathrm{C}<$ stretching modes of dissolved o-cresol consumed during the adsorption process as the potential is lowered. Alternatively, the 1590-1576 and 
1500-1447 $\mathrm{cm}^{-1}$ features can be considered corresponding to surface o-cresol in different adsorption configurations. The potential-dependent reorientation of adsorbed aromatic systems has been reported earlier for several molecules on Pt and Au electrodes [12,31]. These studies postulated a change in the adsorption geometry from ring vertical orientations at high potential or high concentration to ring parallel to the surface at low potential or low concentration.

At potentials between $0.2 \mathrm{~V}$ and $0.0 \mathrm{~V}$, a new negative band at $1419 \mathrm{~cm}^{-1}$ develops in Figure $5 \mathrm{~b}$. This band grows to the detriment of the $1447-\mathrm{cm}^{-1}$ band as the potential is decreased to $0.0 \mathrm{~V}$. The assignment of this vibration is not clear, but it may arise as a consequence of a reorientation process in the interval $0.2-0.0 \mathrm{~V}$ that makes the $1419 \mathrm{~cm}^{-1}$ mode active and turns the mode at $1447 \mathrm{~cm}^{-1}$ inactive.

When the potential decreases to $-0.02 \mathrm{~V}$ (Figure $5 \mathrm{~b}$ ), the group of bands at $1576 \mathrm{~cm}^{-1}, 1447$ and $1365 \mathrm{~cm}^{-1}$ disappear and a new negative band at $1683 \mathrm{~cm}^{-1}$ appears. This latter frequency is within the range of carbonyl functionalities. A weak negative band at $\sim 2100 \mathrm{~cm}^{-1}$ could be ascribed to the C-D stretching mode of deuterated cyclohexyl rings [32]. From these results in conjunction with those taken in water solution (Figure 4b), it can be inferred that adsorbed ocresol is hydrogenated by adsorbed $\mathrm{H}_{2}$ at low overpotential to yield dissolved cyclohexyl products. Therefore, we tentatively assign the absorption at $1683 \mathrm{~cm}^{-1}$ to soluble 2-methylcyclohexanone.

The selective hydrogenation of aromatic alcohols, including phenols and alkyl-substituted phenols, to yield the corresponding cyclohexanone is a well-documented reaction that has a tremendous impact in heterogeneous catalysis [33]. The formation of cyclohexanone products, jointly with cyclohexanol, cyclohexene or even benzene has been reported to occur during either gas-phase or liquid-phase hydrogenation of phenols over supported $\mathrm{Pd}$, Pt and Ni catalysts [33-35]. Also, the electrolytic reduction of phenol and methyl-substituted phenols on bulk Pt and Pt- or Rh-coated carbon electrodes in dilute sulfuric acid solutions has been shown to yield a mixture of cyclohexanone and cyclohexanol, together with cyclohexane formed by hydrogenolysis of the alcohol group [36]. Similarly, mixtures of alkylcyclohexanone and alkyl-cyclohexanol have been obtained by electrolytic hydrogenation of alkyl-substituted phenols on Raney nickel cathodes, the relative abundance of those products being dependant on the particular experimental conditions [37]. It is widely accepted that the 
heterogeneous hydrogenation reaction of aromatic compounds (or more generally of unsaturated compounds) proceeds between the adsorbed organic molecule and adsorbed hydrogen [33]. In electrochemical hydrogenations the adsorbed hydrogen is electrogenerated by reduction of hydronium ions (or water) at low overpotential [37]. A general mechanism has been proposed in which the hydrogenation of adsorbed unsaturated organics competes with the HER via either Tafel or Heyrovski routes [37]:

$$
\begin{aligned}
& \mathrm{H}_{3} \mathrm{O}^{+}\left(\mathrm{H}_{2} \mathrm{O}\right)+\mathrm{e}^{-} \leftrightarrow \mathrm{H}_{\mathrm{ads}}+\mathrm{H}_{2} \mathrm{O}\left(\mathrm{OH}^{-}\right) \\
& \mathrm{X}=\mathrm{Y} \leftrightarrow \mathrm{X}=\mathrm{Y}_{\mathrm{ads}} \\
& \mathrm{X}=\mathrm{Y}_{\mathrm{ads}}+2 \mathrm{H}_{\mathrm{ads}} \leftrightarrow \mathrm{XH}-\mathrm{YH}_{\mathrm{ads}} \\
& \mathrm{XH}-\mathrm{YH}_{\mathrm{ads}} \leftrightarrow \mathrm{XH}-\mathrm{YH}
\end{aligned}
$$

$2 \mathrm{H}_{\mathrm{ads}} \leftrightarrow \mathrm{H}_{2} \quad$ (Competitive Tafel step)

Or $\mathrm{H}_{\mathrm{ads}}+\mathrm{H}_{3} \mathrm{O}^{+}\left(\mathrm{H}_{2} \mathrm{O}\right)+\mathrm{e}^{-} \leftrightarrow \mathrm{H}_{2}+\mathrm{H}_{2} \mathrm{O}\left(\mathrm{OH}^{-}\right) \quad$ (Competitive Heyrovsky step)

In our present case, four adsorbed hydrogen atoms must be involved in the reaction pathway to convert o-cresol into methyl-cyclohexanone.

\section{Conclusions}

The electrochemical behavior of cresol on platinum electrodes has been studied using cyclic voltammetry and in situ FTIR spectroscopy.

The electrooxidation of o-cresol in acid medium on platinum electrodes is inhibited by the formation of a passivating film, which hinders further o-cresol oxidation and the formation of platinum surface oxides. The spectrum of the film shows bands at 1600,1457 and $1019 \mathrm{~cm}^{-1}$ corresponding to aromatic $\mathrm{C}=\mathrm{C}$ stretching vibrations and ring $=\mathrm{C}-\mathrm{H}$ deformation vibrations. These bands permit us to propose that the films created in acid medium maintain the aromatic character. The aromatic moieties are linked through ether $=\mathrm{C}-\mathrm{O}-\mathrm{C}=$ bonds (strong band at $\sim 1150 \mathrm{~cm}^{-1}$ ) and hence points to the polymeric nature of the film. The group of bands 2800 $3000 \mathrm{~cm}^{-1}$ indicate that the methyl group remains attached to the aromatic ring in the polymer. However, the presence of bands associated with carbonyl group could indicate that some oxidized oligomers with quinone groups are also formed. 
From the in situ FTIR results, it can be concluded that the main soluble products formed during the oxidation of o-cresol in acid medium are $\mathrm{CO}_{2}$ and methyl-p-benzoquinone. Moreover, the o-cresol is adsorbed as the potential decreases from 0.2 to $0.0 \mathrm{~V}$ and/or is reoriented on the Pt surface. At potentials below $0.0 \mathrm{~V}$, o-cresol, probably adsorbed o-cresol, suffers hydrogenation to yield solution cyclohexyl molecules. Among them methylcyclohexanone is identified as indicated by the appearance of a band at $1683 \mathrm{~cm}^{-1}$

\section{Acknowledgements}

Financial support by the Ministerio de Economía y Competitividad and FEDER (MAT201015273) and Generalitat Valenciana (PROMETEO/2013/038) projects are gratefully acknowledged. The authors thank to Prof. J.M. Sansano from Organic Chemistry Departament of Alicante University for his fruitfull discussion.

\section{References}

1. M.D. Obradovic, J. Lessard, G. Jerkiewicz, J. Electroanal. Chem., 2010, 649; 248-256.

2. A.A. Isse, A. De Giusti, A. Gennaro, L. Falciola, P.R. Mussini, Electrochim. Acta, 2006, 51; 4956-4964.

3. A.T. Hubbard, Langmuir, 1990, 6;97-105.

4. T. Hartung, H. Baltruschat, Langmuir, 1990, 6; 953-957.

5. M. DeBloisa, J. Lessarda, G. Jerkiewicz, Electrochim. Acta, 2005, 50; 3517-3523.

6. G. Liu, B. Ren, D. Wu, S. Duan, J. Li, J. Yao, R. Gu, Z. Tian, J. Phys. Chem. B, 2006, $110 ; 17498-17506$.

7. H. Baltruschat, U. Schmiemann, Ber. Bunsenges. Phys. 97 (1993) 452/460.

8. F. Montilla, E. Morallón, J.L. Vázquez, Electrochim. Acta, 2002, 47, 4399. 
9. G. Jerkiewicz, M. DeBlois, Z. Radovic-Hrapovic, J.P. Tessier, F. Perreault, J. Lessard, Langmuir 2005, 21, 3511-3520.

10. F. Montilla, E. Morallón, J.L. Vázquez. Electrochemical behaviour of aromatic compounds on platinum electrodes in different aqueous media in «Trends in electrochemistry and corrosion at the beginning of the 21st century» Ed. Universitat de Barcelona, 2004

11. F. Montilla, F. Huerta, E. Morallón, J.L. Vázquez, Electrochim. Acta, 2000, 45, 4271.

12. F. Montilla, E. Morallón, J.L.Vázquez, Langmuir, 2003, 19, 10241.

13. D. Ren, A.T. Hubbard, J. Colloid Interf. Sci. 1999, 209, 435-441.

14. K.H. Kim, S.K. Ihm, J. Hazardous Mat., 2011, 186, 16.

15. H.B. Senturk, D. Ozdes, A. Gundogdu, C. Duran, M. Soylak, J. Hazardous Mat., 2009, 172, 353.

16. I.D. Santos, J.C. Afonso, A.J.B. Dutra, Sep. Purif. Technol., 2010, 76, 151.

17. C. Flox, C. Arias, E. Brillas, A. Savall, K. Groenen-Serrano, Chemosphere, 2009, 74, 1340 .

18. F. Montilla, E. Morallón, J.L. Vázquez, J. Electrochem. Soc., 2005, 152, B421.

19. R. Menini, Y.M. Henuset, F. Fournier, J. Appl. Electrochem., 2005, 35, 625.

20. J.L. Nava, F. Núñez, I. González, Electrochim. Acta, 2007, 52, 3229.

21. M. Gattrell, D.W. Kirk, J. Electrochem. Soc., 1993, 140, 903.

22. M. Gattrell, D.W. Kirk, J. Electrochem. Soc., 1993, 140, 1534.

23. H.J. Salavagione, J. Arias, P. Garcés, E. Morallón, C. Barbero, J.L. Vázquez, J. Electroanal. Chem, 2004, 565, 375.

24. M. Ferreira, H. Varela, R.M. Torresi, G. Tremiliosi-Filho, Electrochim. Acta, 2006, 52, 434.

25. S. Andreescu, D. Andreescu, O.A. Sadik, Electrochem. Comm., 2003, 5, 681. 
26. R. Lapuente, F. Cases, P. Garcés, E. Morallón, J.L Vázquez, J. Electroanal. Chem., 1998, 451, 163.

27. R Lapuente, C Quijada, F Huerta, F Cases, J.L. Vázquez, Polym. J., 2003, 35, 911.

28. N.B. Colthup, L.H. Daly, S.E. Wiberley, Introduction to Infrared and Raman spectroscopy, $3^{\text {rd }}$ Ed., Academic Press, San Diego, 1990.

29. G. Socrates, Infrared and Raman Characteristic Group Frequencies, third ed., Wiley, New York, 2001.

30. NIST Chemistry WebBook; National Institute of Standards and Technology; 2011, http://webbook.nist.gov/cgi/cbook.cgi?Name=methyl-benzoquinone \&Units=SI $\& c I R=$

31. M.P. Soriaga, P.H. Wilson, A.T. Hubbard, C.S. Benton, J. Electroanal. Chem., 1982, $142,317$.

32. A.R. Almeida, J. A. Moulijn, G. Mul, J. Phys. Chem. C, 2008, 112, 1552.

33. E.-J. Shin, M.A. Keane, J. Catal., 1998, 173, 450.

34. S. Sciré, C. Crisafulli, R. Maggiore, S. Minicò, S. Galvagno, Appl. Surf. Sci., 1996, 93, 309

35. S. Sciré, S. Minicò, C. Crisafulli, Appl. Catal. A, 2002, 235, 21.

36. L.L. Miller, L. Christensen, J. Org. Chem., 1978, 43, 2059.

37. H. Ilikti, N. Rekik, M. Thomalla, J. Appl. Electrochem., 2004, 34, 127. 


\section{Figure captions}

Figure 1. Cyclic voltammograms for a platinum electrode immersed in a $0.5 \mathrm{M} \mathrm{H}_{2} \mathrm{SO}_{4}+$ $10^{-3} \mathrm{M}$ o-Cresol. $v=50 \mathrm{mV} \cdot \mathrm{s}^{-1}$. (-) first, (-- ) second and (---) fifth cycle up to $1.8 \mathrm{~V}$.

Figure 2. Voltammetric behaviour of a platinum electrode coated by the polymeric film created in Fig. 1, in $0.5 \mathrm{M} \mathrm{H}_{2} \mathrm{SO}_{4}$ solution. $v=50 \mathrm{mV} \mathrm{s}^{-1}$. (-- ) test solution.

Figure 3. FTIR-ATR spectrum of a polymer film formed on platinum electrode by electroxidation of $10^{-3} \mathrm{M}$ o-cresol in $0.5 \mathrm{M} \mathrm{H}_{2} \mathrm{SO}_{4}$ during $2 \mathrm{~h}$ at $1.8 \mathrm{~V}$.

Figure 4. FTIR spectra collected for a polycrystalline platinum electrode in $0.5 \mathrm{M} \mathrm{H}_{2} \mathrm{SO}_{4}+$ $10^{-3} \mathrm{M}$ o-cresol solution during (a) oxidation up to $1.4 \mathrm{~V}$, (b) reduction down to $-0.05 \mathrm{~V} .100$ interferograms. p-polarised light. Reference potential 0.3 V. Water solution;

Figure 5. FTIR spectra collected for a polycrystalline platinum electrode in $0.5 \mathrm{M} \mathrm{H}_{2} \mathrm{SO}_{4}+$ $10^{-3} \mathrm{M}$ o-cresol solution during (a) oxidation up to $1.4 \mathrm{~V}$ and (b) reduction down to $-0.02 \mathrm{~V}$. 100 interferograms. p-polarised light. Reference potential $0.3 \mathrm{~V}$. Deuterated water solution. 
Click here to download Figure: figures.docx

Fig 1

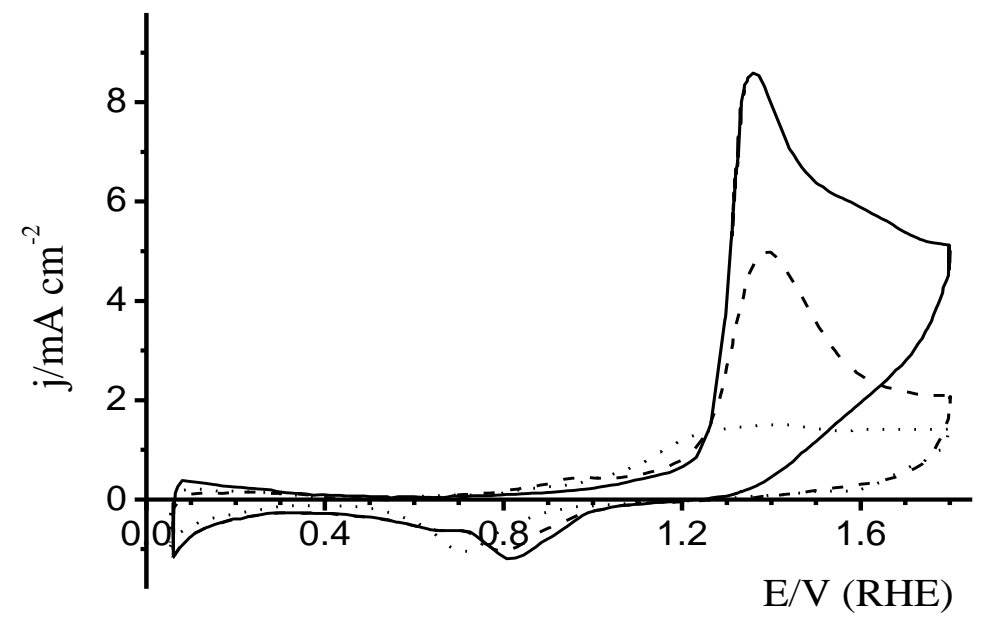


Fig 2

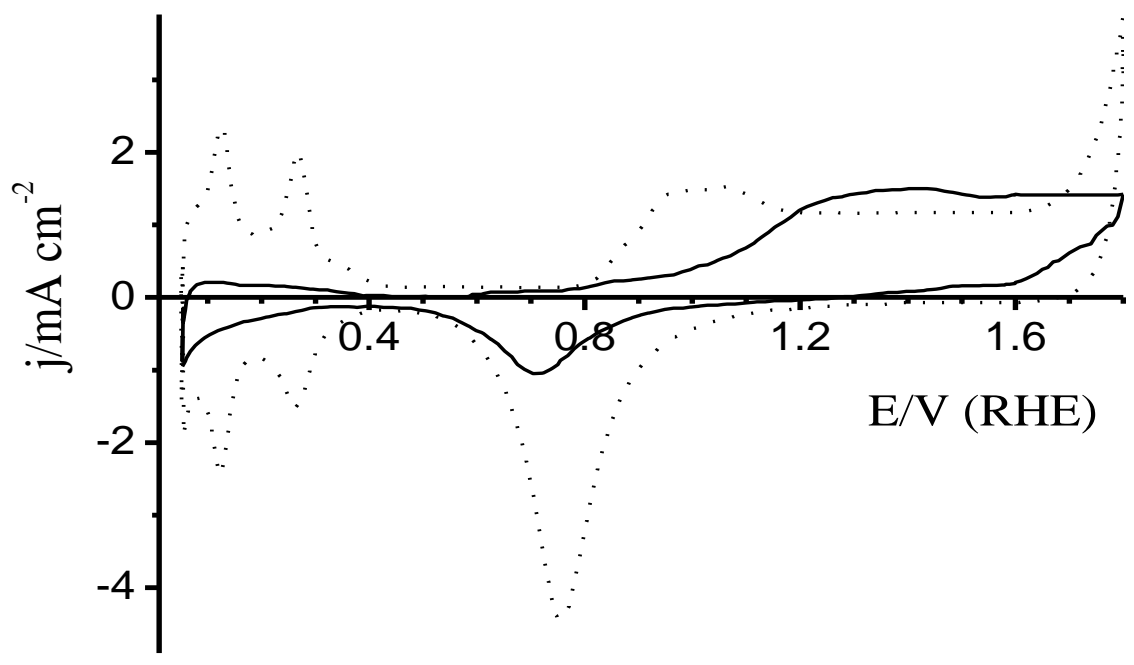


Fig 3

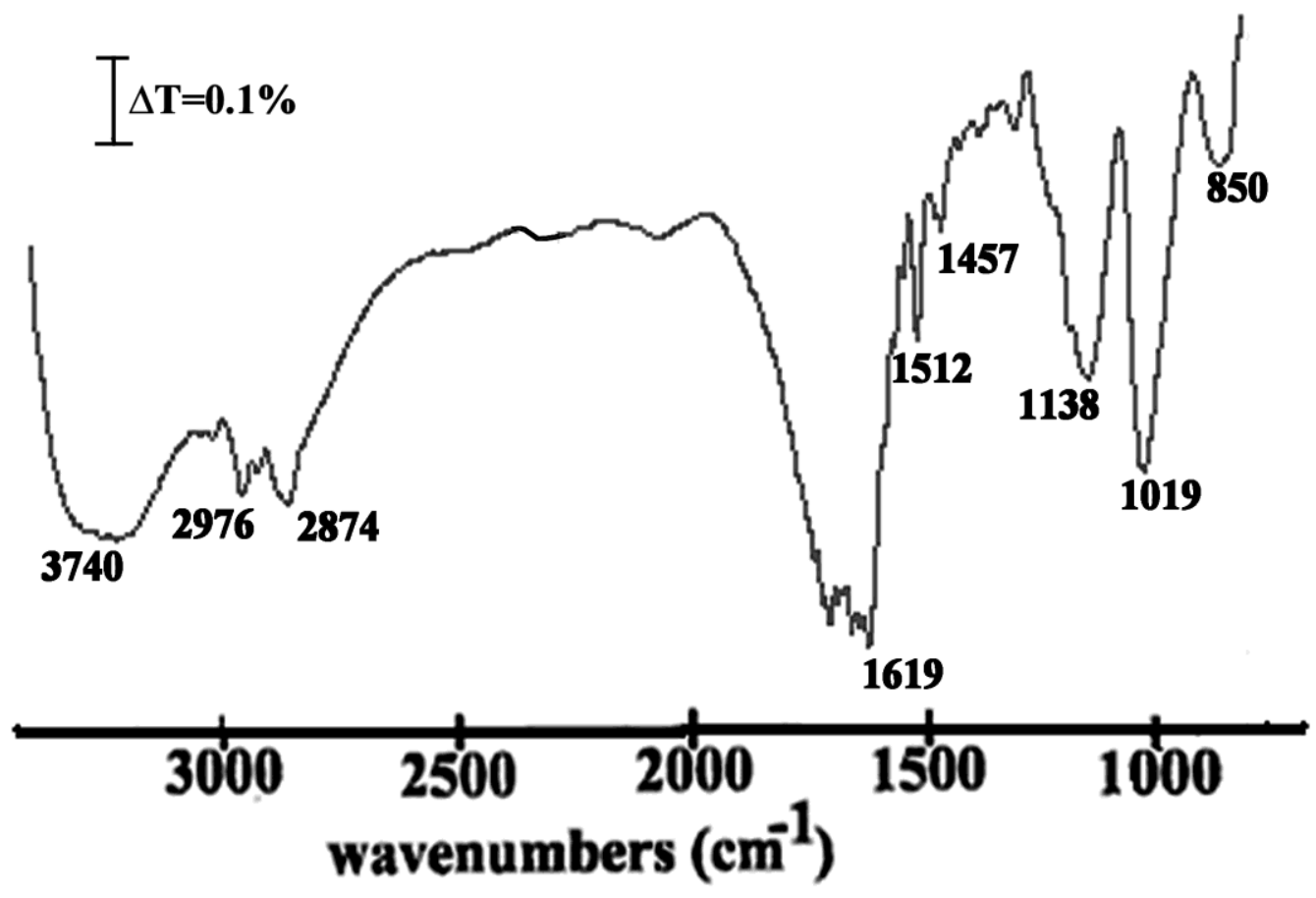


Fig 4a

a

$$
0.5 \mathrm{~V}
$$
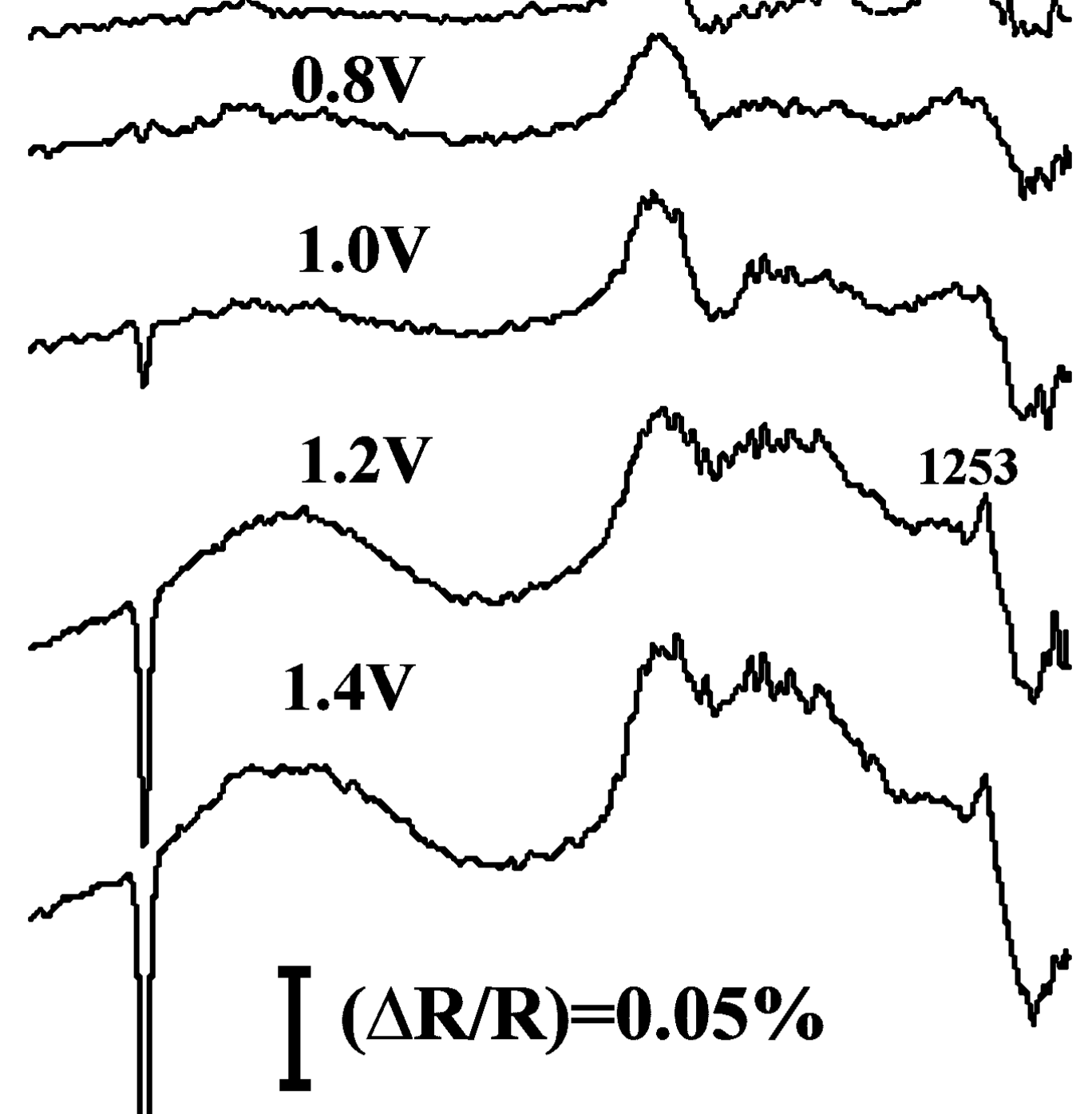

2345

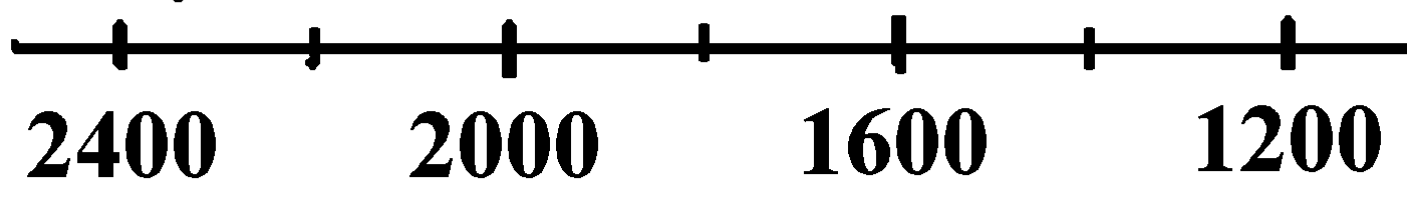

wavenumbers / $\mathrm{cm}^{-1}$ 
Fig 4b

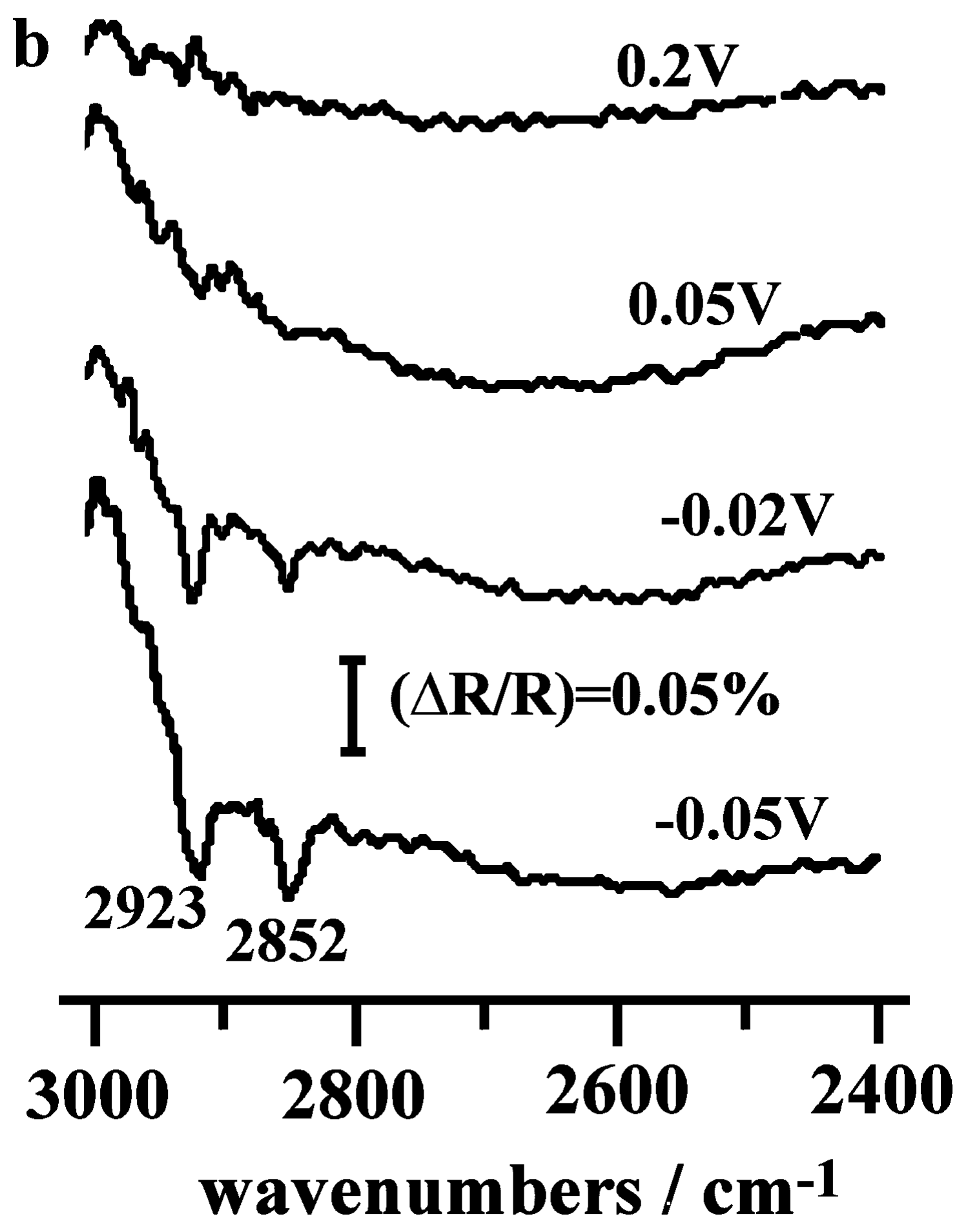


Fig 5a

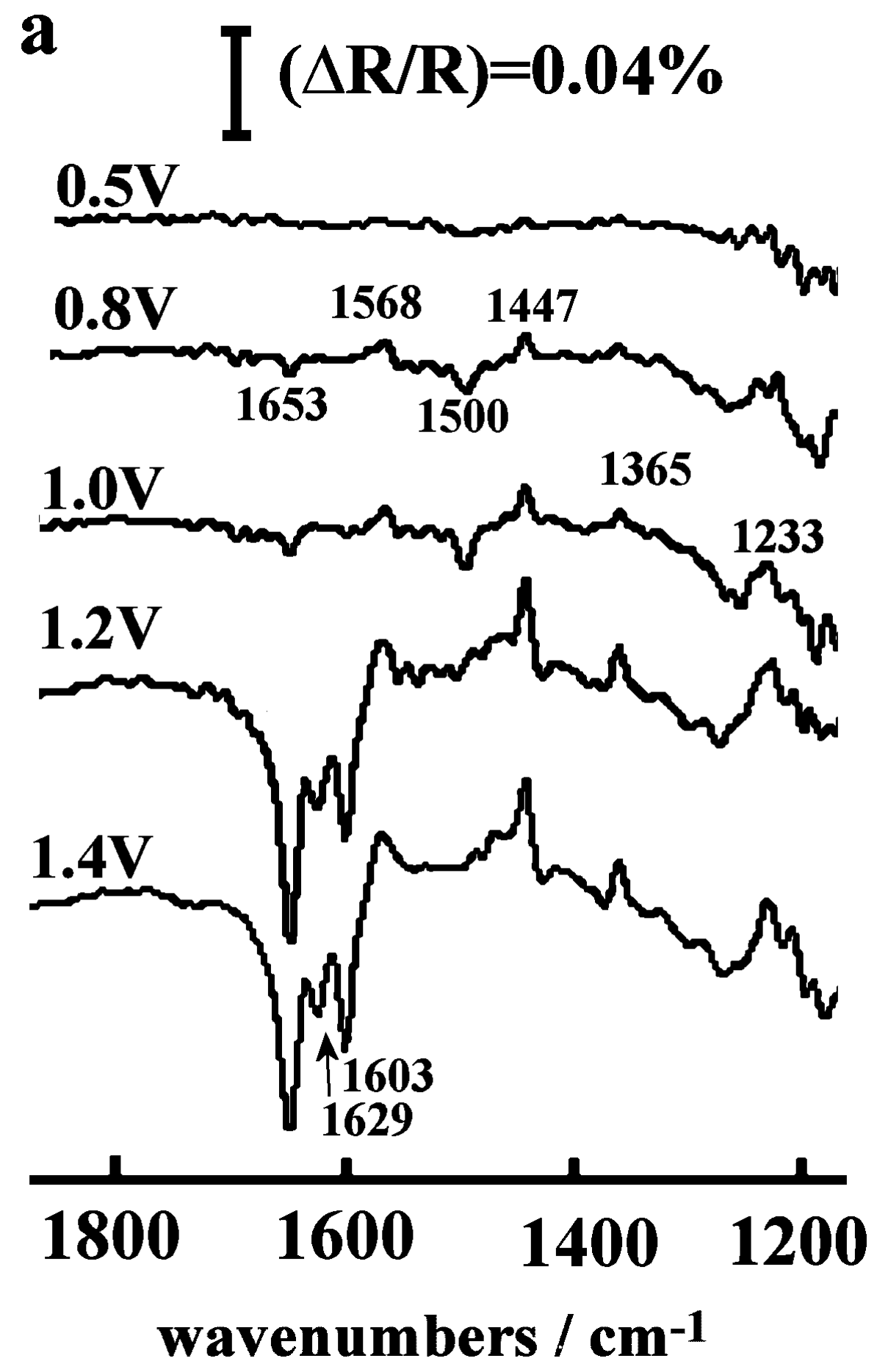


Fig 5b

b

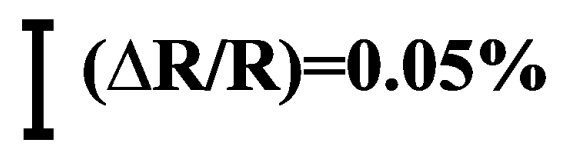

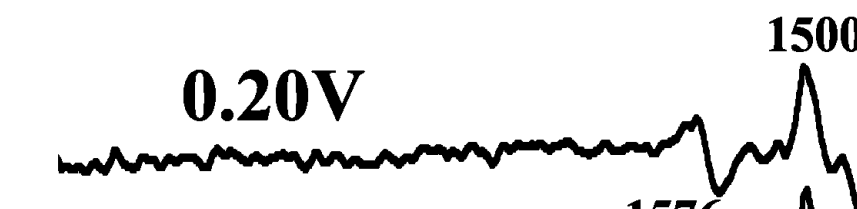
1500

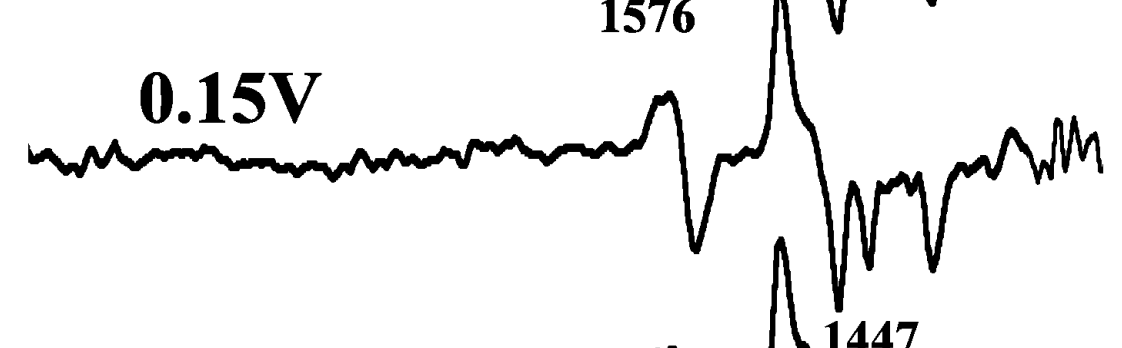

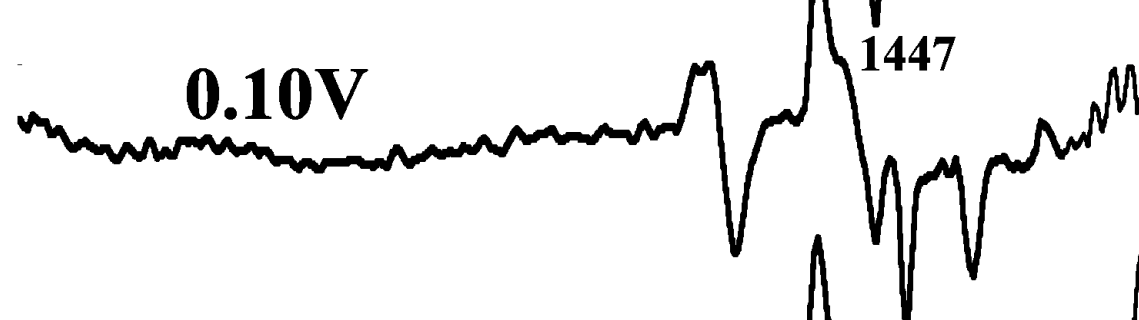

$0.05 \mathrm{~V}$

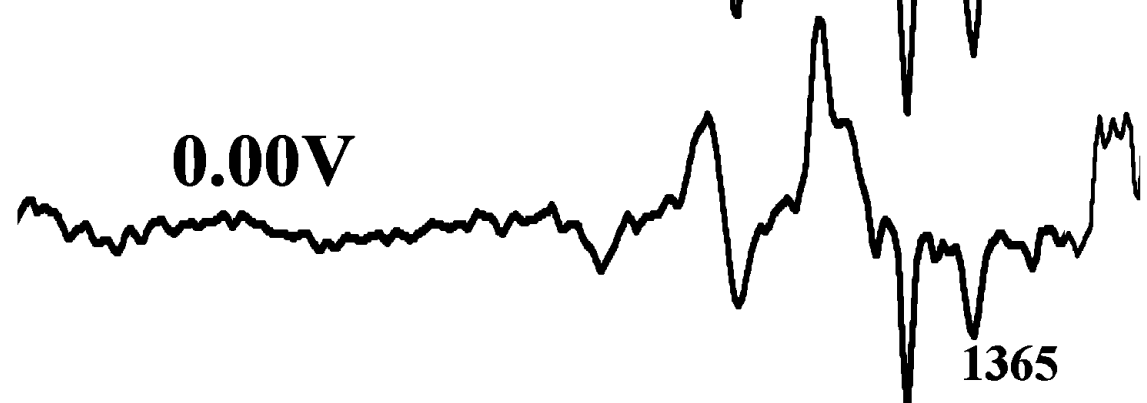

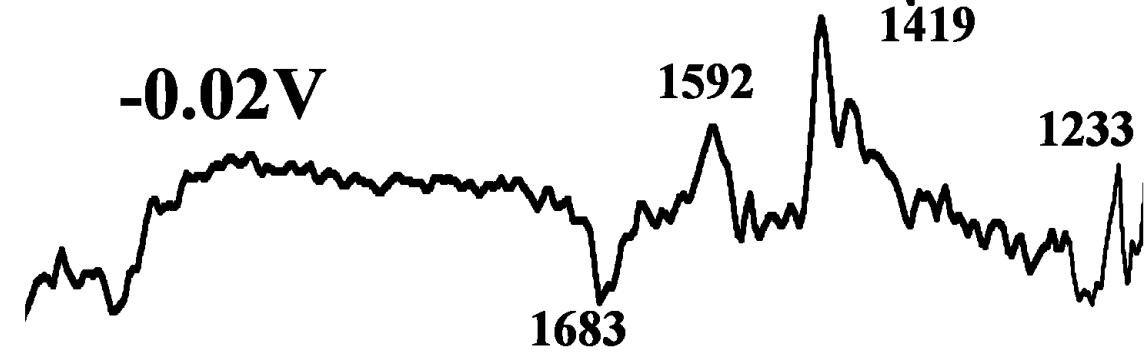

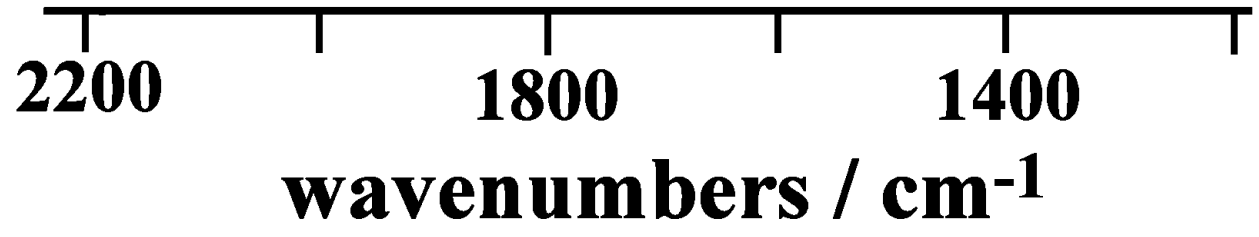

